\title{
Faktor-faktor yang Memengaruhi Kesiapan Penerapan Knowledge Management (KM Readiness) pada Organisasi Non-profit
}

\author{
Iklima Ermis Ismail \\ Jurusan Teknik Informatika dan Komputer \\ Politeknik Negeri Jakarta \\ Depok, Indonesia \\ iklima.ermis@gmail.com
}

\author{
Dana Indra Sensuse \\ Fakultas Ilmu Komputer \\ Universitas Indonesia \\ Depok, Indonesia \\ dana@cs.ui.ac.id
}

Diterima: 20 Maret 2015. Disetujui: 25 April 2015. Dipublikasikan: Mei 2015

\begin{abstract}
Abstrak - Pada penelitian ini diajukan tujuh faktor yang memengaruhi KM readiness, yaitu budaya organisasi, struktur organisasi, teknologi informasi, strategi KM pada ONP, ekspektasi individu terhadap performa KM, ekspektasi individu terhadap kemudahan penggunaan KM, dan keinginan terlibat pada proses KM, yaitu Socialization, Externalization, Combination, Internalization (SECI). Pengujian kerangka konsep penelitian dilakukan dengan menyebarkan kuesioner kepada lembaga amil zakat (LAZ), diperoleh 124 responden. Pengolahan data menggunakan statistik Partial Least Square-Structural Equation Modelling (PLS-SEM). Hasil pengolahan data menunjukkan bahwa hanya budaya organisasi yang mendukung terhadap proses-proses KM (SECI) pada faktor organisasi. Pada faktor penerimaan individu hanya ekspektasi terhadap kemudahan penggunaan KM yang mendukung terhadap proses-proses KM (SECI). Strategi KM pada ONP mendukung terhadap proses-proses KM (SECI), serta proses-proses SECI yang mendukung kesiapan penerapan KM pada ONP.
\end{abstract}

Kata Kunci: knowledge management (KM), KM-enabler, KM readiness, organisasi non-profit (ONP), SECI.

\section{PENDAHULUAN}

Penelitian menunjukkan bahwa pengetahuan menjadi alat atau tools penting untuk memperkuat nilai kompetitif organisasi. Kunci utama keberhasilan suatu organisasi dilihat dari kemampuan organisasi mendapatkan, mengirimkan dan melindungi pengetahuan, bahkan lebih jauh adalah dengan menciptakan pengetahuan[1]. Knowledge Management (KM) pada suatu organisasi menjadi penting dalam suatu kondisi dimana permasalahan-permasalahan yang muncul ketika suatu tugas mendesak untuk segera diselesaikan, namun informasi yang tersedia untuk mengambil keputusan terkait tugas tersebut sangat terbatas[2]. Hal ini bukan karena tidak adanya informasi, namun karena informasi tidak dapat diakses dengan mudah atau karena pengaturan terhadap informasi yang terlalu hati-hati. KM merupakan metodologi dalam menghadirkan pembelajaran (learning) dan inovasi untuk meningkatkan kinerja atau performa suatu organisasi[3].

Sektor non-profit atau dikenal juga dengan istilah Organisasi Non-Profit (ONP) merupakan organisasi yang berdiri untuk mewujudkan perubahan pada individu atau komunitas, bukan mencari keuntungan dan laba, melainkan untuk menyalurkan dana kepada masyarakat sesuai dengan visi dan misi organisasi. Sektor non-profit kurang memperhatikan proses pembentukan pengetahuan, dan lebih menekankan pada kolaborasi, berbagi (sharing) pengetahuan dan penyebaran pengetahuan [4].

Sektor non-profit dicirikan dengan beragamnya struktur organisasi, tingginya knowledge-intensive organisasi dan tingginya tingkat turn-over karyawan. Tingginya turn-over karyawan akan mempersulit organisasi dalam proses KM, karena pengetahuan organisasi utamanya berasal dari karyawan [1]. Sebagian besar ONP menganggap bahwa keberhasilan organisasi diukur dari banyaknya program yang sukses terlaksana, kemudian direplikasi untuk mengulang keberhasilan program, namun bukan untuk membuat ulang segala fitur-fitur keberhasilan [5]. Untuk semua permasalahan yang dihadapi oleh ONP tersebut, maka diperlukan suatu mekanisme pembelajaran yang dapat mengelola pengetahuan-pengetahuan organisasi yang mendorong organisasi menjadi organisasi pembelajar, yaitu manajemen pengetahuan (KM). Sebelum diterapkan suatu KM pada suatu organisasi maka langkah awal yang harus dilakukan adalah mengukur atau menilai kesiapan organisasi untuk menerapkan KM agar ketika organisasi menerapkan KM (KM readiness) agar tidak terjadi kegagalan dalam penerapan KM, karena kondisi organisasi (orang dan lingkungan) tidak siap menerima KM. 
Pada penelitian ini, penulis akan melakukan analisa faktor-faktor yang memengaruhi kesiapan penerapan KM (KM readiness) pada ONP (studi kasus pada Lembaga Amil Zakat (LAZ)) menggunakan model yang diusulkan. Hal ini dilakukan untuk menjawab permasalahan utama penerapan KM pada ONP, yaitu apa saja faktorfaktor yang memengaruhi kesiapan penerapan KM (KM readiness) pada ONP. Berdasarkan permasalahan penelitian, maka tujuan yang ingin dicapai dari penelitian ini adalah untuk membangun suatu model yang dapat digunakan untuk menilai kesiapan penerapan KM pada ONP didasarkan pada faktor-faktor yang diusulkan pada penelitian ini. Penelitian ini diharapkan dapat memberikan suatu wawasan terhadap perbaikan performa dan inovasi ONP, khususnya LAZ dengan memaksimalkan proses-proses KM.

\section{TINJAUAN TEORITIS}

\section{A. Manajemen Pengetahuan}

Knowledge management (KM) merupakan bantuan untuk learning organisasi dengan menyiapkan karyawan, alur kerja, dan tools untuk membantu hadirnya inovasi, pengumpulan, penyebaran dan penggunaan pengetahuan [6]. KM sebagai suatu proses yang membantu organisasi mengidentifikasi, memilih, mengorganisasi, menyebarkan dan men-transfer keahlian dan informasi penting yang menjadi bagian dari memori organisasi dan umumnya berada dalam suatu organisasi dalam suatu cara yang tidak terstruktur [7].

Nonaka dan Takeuchi menyusun empat proses KM dalam suatu model yang dikenal dengan model SECI, yang terdiri dari proses Sosialisasi (Socialization), Eksternalisasi (Externalization), Kombinasi (Combination) dan Internalisasi (Internalization) [8].

\section{B. $\quad$ KM Readiness}

KM readiness sebagai kesiapan organisasi, departemen atau kelompok kerja agar berhasil menerapkan, menggunakan dan mendapatkan keuntungan KM secara sukses[9]. Kesiapan untuk melakukan atau mengeksekusi suatu hal tidak cukup hanya dengan keinginan atau kebutuhan saja, namun juga harus diiringi dengan adanya kemampuan dan sumber daya untuk melakukannya[10].

\section{KM Readiness pada ONP}

Penelitian yang menjadi acuan utama adalah Knowledge Management for Non-profits: A Strategy for Organizational Sustainability[11].

\section{Kerangka Konsep Penelitian}

Pada penelitian ini diajukan beberapa hipotesis, seperti ditunjukkan pada Tabel 1.

\section{TABEL 1. HIPOTESIS PENELITIAN}

\begin{tabular}{|l|l|}
\hline No & \multicolumn{1}{|c|}{ Hipotesis } \\
\hline H1 & $\begin{array}{l}\text { Budaya organisasi berpengaruh positif dan signifikan } \\
\text { terhadap KM readiness. [12] }\end{array}$ \\
\hline H2 & $\begin{array}{l}\text { Struktur organisasi berpengaruh positif dan signifikan } \\
\text { terhadap KM readiness[13]. }\end{array}$ \\
\hline H3 & $\begin{array}{l}\text { Teknologi Informasi berpengaruh positif dan } \\
\text { signifikan terhadap KM readiness[13]. }\end{array}$ \\
\hline H4 & $\begin{array}{l}\text { Budaya organisasi berpengaruh positif dan signifikan } \\
\text { terhadap SECI[12]. }\end{array}$ \\
\hline H5 & $\begin{array}{l}\text { Struktur organisasi berpengaruh positif dan signifikan } \\
\text { terhadap SECI[12]. }\end{array}$ \\
\hline H7 & $\begin{array}{l}\text { Teknologi Informasi berpengaruh positif dan signifikan } \\
\text { terhadap SECI[12]. }\end{array}$ \\
\hline H8 \\
signifikan terhadap SECI[12]. \\
\hline H9 & $\begin{array}{l}\text { Ekspektasi performa dari KM berpengaruh positif dan } \\
\text { signifikan terhadap KM readiness[13]. }\end{array}$ \\
\hline H10 & $\begin{array}{l}\text { Ekspektasi kemudahan penggunaan KM berpengaruh } \\
\text { positif dan signifikan terhadap SECI[14]. } \\
\text { dan signifikan terhadap KM readiness. }\end{array}$ \\
\hline H11 & $\begin{array}{l}\text { Konsep KM ONP berpengaruh positif dan signifikan } \\
\text { terhadap KM readiness } .\end{array}$ \\
\hline H12 & $\begin{array}{l}\text { Konsep KM pada ONP berpengaruh positif dan } \\
\text { signifikan terhadap SECI. }\end{array}$ \\
\hline H13 & $\begin{array}{l}\text { SECI berpengaruh positif dan signifikan terhadap KM } \\
\text { readiness. }\end{array}$ \\
\hline
\end{tabular}

\section{METODE PENELITIAN}

Pengambilan sampel dilakukan dengan teknik convenience sampling. Sampel yang digunakan pada penelitian ini sebanyak lima organisasi non-profit, masing-masing lembaga sebanyak 30 responden. Metode analisis data yang digunakan yaitu PLS, dengan bantuan software SmartPLS 2.0 M3. Gambar 1 menunjukkan model penelitian yang dilakukan.

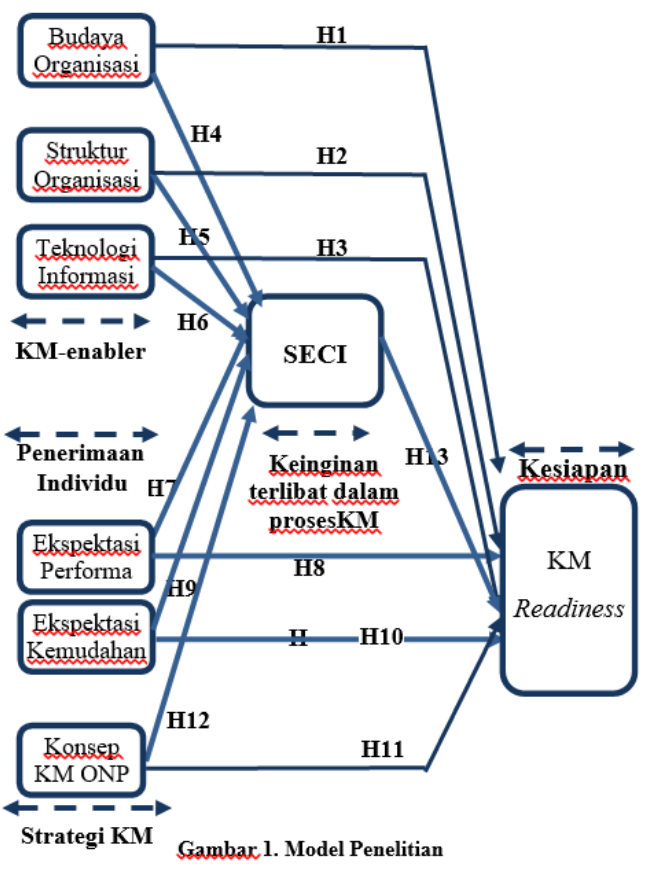




\section{HASIL PENELITIAN}

Dari penyebaran 150 kuesioner tersebut, sebanyak 124 kuesioner yang dapat diolah. Dari hasil pengolahan diagram jalur model terdapat beberapa variabel yang dihapus, karena nilai loading factor-nya $<0,70$. Diagram jalur model yang diperoleh ditunjukkan pada Gambar 2.

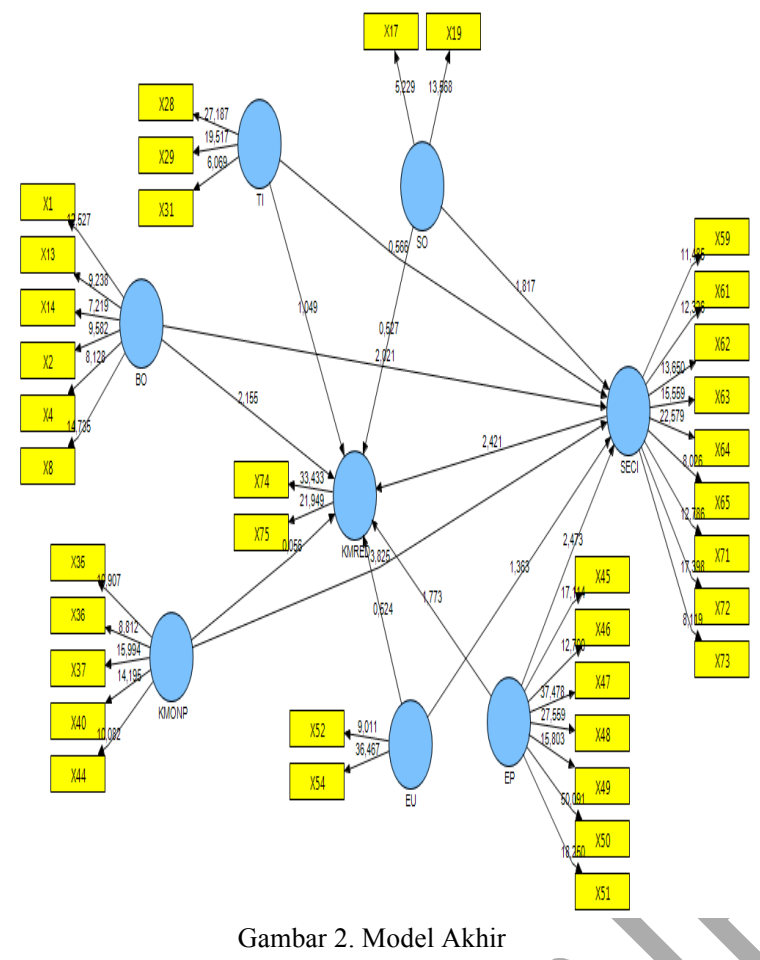

Nilai $R$-square yang diperoleh diagram jalur model ditunjukkan pada Tabel 2

\begin{tabular}{|l|c|}
\multicolumn{2}{c}{ TABEL 2. $R$-SQUARE } \\
\hline \multicolumn{1}{|c|}{ S square } \\
\hline KMRED & 0,29 \\
\hline SECI & 0,47 \\
\hline
\end{tabular}

Mengacu kepada Chin [15], maka nilai variabel Endogen SECI $(0,47)$ berarti kuat, sedangkan nilai variabel Endogen KMRED yang berarti bahwa variabel termasuk dalam kategori moderat $(0,29)$. Variabel SECI memiliki nilai $R$ square sebesar 0,47 yang berarti $47 \%$ varian $\mathrm{BO}$, SO, TI, KMONP, EP dan EU dapat menjelaskan variabel SECI, sedangkan sisanya dijelaskan oleh variabel lain di luar model penelitian.

Uji fit model, untuk mengukur keseluruhan prediksi model menggunakan kriteria Goodness of Fit atau GoF indeks yang diajukan oleh Tenenhaus[16].

GoF index model diperoleh sebagai berikut :

$$
\text { GoF }=\sqrt{\text { communality }} * \overline{R^{2}}
$$

$\mathrm{GoF}=0,514124$
Nilai GoF yang diperoleh sebesar 0,51, mengacu pada Ghozali[16], maka dapat disimpulkan bahwa GoF model termasuk pada kategori large. Hal ini berarti bahwa model dapat dikatakan bagus dan memiliki kekuatan untuk menjelaskan fenomena KM readiness pada ONP.

Selanjutnya adalah pengujian hipotesis, dengan melihat nilai T-statistics yang diperoleh model secara keseluruhan seperti yang ditunjukkan pada Tabel 3 .

\begin{tabular}{|c|c|c|c|c|}
\hline & Variabel & $\begin{array}{c}\text { Original } \\
\text { Sample }\end{array}$ & T-Statistics & Ket \\
\hline H1 & $\begin{array}{l}\text { BO -> } \\
\text { KMRED }\end{array}$ & $-0,25$ & & Ditolak \\
\hline H2 & $\begin{array}{l}\mathrm{SO}-> \\
\text { KMRED }\end{array}$ & 0,05 & 0,53 & Ditolak \\
\hline H3 & $\begin{array}{l}\text { TI -> } \\
\text { KMRED }\end{array}$ & & & Ditolak \\
\hline H4 & BO $->$ SECI & 0,19 & 2,02 & Diterima \\
\hline H5 & SO -> SECI & 0,14 & 1,82 & Ditolak \\
\hline H6 & TI $->$ SECI & $-0,048$ & 0,57 & Ditolak \\
\hline H7 & EP $\rightarrow$ SECI & 0,21 & 2,47 & Diterima \\
\hline H8 & $\begin{array}{l}\text { EP -> } \\
\text { KMRED }\end{array}$ & 0,21 & 1,77 & Ditolak \\
\hline H9 & EU -> SECI & 0,10 & 1,36 & Ditolak \\
\hline $\begin{array}{l}\text { H1 } \\
0\end{array}$ & $\begin{array}{l}\text { EU -> } \\
\text { KMRED }\end{array}$ & 0,06 & 0,52 & Ditolak \\
\hline $\begin{array}{l}\text { H1 } \\
1\end{array}$ & $\begin{array}{l}\text { KMONP -> } \\
\text { KMRED }\end{array}$ & 0,01 & 0,06 & Ditolak \\
\hline $\begin{array}{l}\text { H1 } \\
2\end{array}$ & $\begin{array}{l}\text { KMONP -> } \\
\text { SECI }\end{array}$ & 0,35 & 3,83 & Diterima \\
\hline $\begin{array}{l}\text { H1 } \\
3\end{array}$ & $\begin{array}{l}\text { SECI -> } \\
\text { KMRED }\end{array}$ & 0,43 & 2,42 & Diterima \\
\hline
\end{tabular}

\section{PEMBAHASAN}

Budaya organisasi pada ONP saat ini belum dapat memberikan pengaruh positif terhadap kesiapan implementasi KM pada ONP namun mendukung terbentuknya proses KM (SECI). Kondisi ini bisa jadi disebabkan karena belum terciptanya suatu rutinitas yang berkaitan dengan berbagi pengetahuan serta pengalaman antar anggota organisasi secara terorganisir. Kondisi turn-over pada ONP merupakan salah satu faktor yang memiliki efek negatif terhadap kesiapan penerapan KM pada ONP, karena perhatian organisasi akan tersita untuk memikirkan masalah turn-over pada ONP. Budaya organisasi telah diidentifikasi sebagai katalis utama pada proses terbentuk dan berbagi pengetahuan[13]. Budaya organisasi yang bersifat knowledge-friendly merupakan kondisi pendukung yang sangat penting bagi berhasilnya KM pada suatu organisasi[17]. Tanpa disadari oleh anggota organisasi mereka telah melakukan proses KM, namun karena belum terorganisir dengan baik dan belum dijadikan suatu regulasi, menjadikan efek dari proses KM yaitu pembelajaran (learning) tidak optimal. 
Struktur organisasi pada ONP dapat memberikan pengaruh positif, namun tidak signifikan memengaruhi kesiapan penerapan KM, namun tidak signifkan memengaruhi terlaksananya proses-proses KM (SECI). Kondisi ini dapat terjadi karena dipengaruhi oleh formalisasi aturan organisasi yang masih kaku, serta belum adanya strategi bisnis organisasi dalam mengarahkan dan memotivasi karyawan ONP terhadap kegiatan dan proses KM sehingga tidak muncul inisiatif dan keberanian mengambil keputusan dan resiko. Struktur organisasi akan memengaruhi arus informasi sebagaimana konteks interaksi manusia [12]. Meningkatkan partisipasi anggota dalam inisiasi KM dan menyediakan ruang pada proses pengambilan keputusan berperan penting dalam membangun komitmen anggota[18]. Kondisi ONP yang cenderung terbuka dan lebih fleksibel sebenarnya menjadi salah satu faktor pendukung kemudahan dalam proses KM (SECI). Gaya kepemimpinan yang bersifat delegatif merupakan gaya yang memperlihatkan kesiapan implementasi KM, karena pimpinan mempercayai bahwa informasi yang tidak dimilikinya paling banyak beredar di tengah anggota[19]. Pemimpin pada kondisi ini menginginkan pengembangan informasi sehingga lebih mudah mendorong terjadinya berbagi pengetahuan dan proses-proses KM lainnya (SECI) Mekanisme reward (penghargaan) juga dapat menjadi salah satu kebijakan yang tidak hanya mendorong orang untuk mengumpulkan dan berbagi pengetahuan, tapi juga memotivasi orang untuk aktif mencari pengetahuan di luar, dan membentuknya menjadi suatu pengetahuan personal baru[20]. Namun, kondisi ini belum terpenuhi oleh ONP saat ini.

Layanan teknologi informasi pada ONP berpengaruh positif terhadap kesiapan penerapan $\mathrm{KM}$, namun tidak signifikan memengaruhi kesiapan penerapan KM. Meskipun layanan teknologi informasi bukan merupakan faktor utama terbentuknya kesiapan menerapkan KM, namun layanan teknologi informasi merupakan faktor pendukung terbentuknya kondisi yang kondusif untuk menerapkan KM. Faktor teknologi informasi merupakan faktor penting jika perusahaan akan membangun suatu sistem KM [20]. Banyak ONP menganggap teknologi sebagai barang mewah[4]. Kondisi ini bisa menjadi faktor yang memengaruhi kesiapan teknologi informasi dalam mendukung kesiapan implementasi KM. Layanan teknologi memberikan pengaruh negatif, dan tidak signifikan memengaruhi proses KM (SECI), artinya jika layanan teknologi informasi menurun, maka proses SECI akan meningkat. Hal ini bertentangan dengan teori-teori sebelumnya yang menyatakan bahwa teknologi informasi dapat membantu meningkatkan proses KM (SECI). Aspek teknologi sebenarnya sangat berperan penting bagi ONP, seperti mengiklankan layanan, mengkomunikasikan tujuan dan misi organisasi, serta merekrut relawan. Meskipun potensialnya tinggi, namun seringkali pihak manajemen tidak memiliki strategi yang komprehensif dalam memanfaatkan potensi teknologi ini. Contohnya internet yang hanya digunakan sebatas penggunaan umum untuk administrasi dan operasional, padahal dapat digunakan untuk mengelola email donatur dan mengirimkan buletin organisasi[21].

Ekspektasi terhadap performa memberikan pengaruh positif, namun tidak signifikan, artinya jika ekspektasi pengguna terhadap performa kerja jika diterapkan KM meningkat, maka proses-proses KM (SECI) juga akan meningkat, begitu juga sebaliknya. Hal ini menunjukkan bahwa anggota organisasi memiliki harapan bahwa implementasi KM akan membantu meningkatkan performa kerja. Penerimaan ini merupakan langkah awal untuk membuat suatu kebijakan pihak manajemen untuk melaksanakan proses KM (SECI).

Pada ONP saat ini belum bisa memberikan dukungan terhadap kesiapan implementasi KM. Kondisi ini menunjukkan bahwa anggota organisasi pada ONP baru siap untuk melaksanakan prosesproses KM (SECI), namun belum siap terhadap suatu perubahan. Hal yang perlu dipersiapkan oleh manajemen adalah memberikan pelatihan kepada anggota organisasi.

Ekspektasi usaha atau kemudahan terhadap kehadiran dan penggunaan KM berpengaruh secara positif, namun tidak signifikan memengaruhi proses KM (SECI). Kondisi ini dapat saja disebabkan persepsi anggota organisasi yang menghindari perubahan dan tidak ingin mencoba suatu cara atau mekanisme yang baru karena sulit atau memakan waktu lama. Sedangkan fungsi atau peran sebagai karyawan atau relawan ONP yang lebih banyak berada di lapangan dan selalu bertemu dengan situasi baru sebenarnya mendorong proses pengelolaan pengetahuan-pengetahuan baru, tapi terhambat karena adanya persepsi tersebut.

Ekspektasi kemudahan penggunaan jika diterapkan KM memberikan pengaruh positif, namun tidak signifikan. Kondisi ini dapat terjadi karena tingkat pemahaman anggota organisasi yang berbeda terhadap aspek teknologi, selain itu karena adanya resistensi terhadap perubahan sehingga merasa sulit jika dihadapkan dengan suatu hal yang baru[4].

Strategi KM pada ONP berpengaruh positif terhadap kesiapan implementasi $\mathrm{KM}$, namun tidak signifikan. Untuk melaksanakan proses KM, mereka sudah siap, namun masih terkendala dengan terbatasnya sumber-sumber informasi dan pengetahuan yang berkaitan dengan visi-misi, logo dan pencitraan ONP. Hal ini sesuai dengan bahwa 
adanya resistensi anggota ONP terhadap perubahan dan kebaruan merupakan bukti terbatasnya sumber daya dan kepedulian mereka terhadap keuntungan pengetahuan[4].

Strategi KM pada ONP memberikan pengaruh positif dan signifikan terhadap proses KM (SECI) pada ONP. Hal ini membuktikan bahwa secara personal, anggota organisasi telah melakukan proses-proses KM, seperti diskusi, bertanya, mencari sumber pengetahuan lain secara mandiri.

SECI memengaruhi KM readiness secara positif dan signifikan. Hal ini menunjukkan bahwa keinginan individu organisasi untuk terlibat secara langsung pada proses KM (SECI) berada pada kondisi yang mendukung kesiapan ONP untuk menerapkan KM.

\section{KESIMPULAN}

Dari hasil pengolahan data, diperoleh empat faktor yang memengaruhi kesiapan KM pada ONP. Faktor yang berpengaruh terhadap kesiapan implementasi KM, yaitu SECI. Sedangkan tiga faktor lainnya, yaitu strategi KM pada ONP, budaya organisasi, dan ekspektasi performa terhadap KM berpengaruh terhadap SECI, yang berarti ketiga faktor tersebut mendukung proses KM, namun belum berpengaruh terhadap kesiapan KM. Secara karakter individu, anggota ONP mendukung terhadap kesiapan penerapan KM, walaupun pada dasarnya mereka belum memiliki pengetahuan mendalam mengenai proses KM. Infrastruktur teknologi dan kebijakan manajemen sama sekali belum berpengaruh terhadap kesiapan penerapan KM pada ONP. Hal ini dikarenakan KM masih merupakan hal baru bagi ONP dan belum mendapat perhatian.

Beberapa saran yang dapat disampaikan. antara lain memperbanyak jumlah sampel penelitian sehingga hasil yang diperoleh lebih baik. Ke depannya diharapkan dapat dilakukan pendekatan mengukur faktor penerimaan individu dengan memerhatikan kondisi sosial responden.

\section{REFERENSI}

[1] Hsu, R. C., Lawson, D., dan Liang, T.P., (2007) Factors Affecting Knowledge Management of Taiwan Small and Medium-Sized Enterprised, International Journal Management and Enterprise Development, Vol. 4, No. 1. pp. $30-51$

[2] Czuchry, A. J., dan Yasin, M. M., (2003) Managing the Project Management Process, Industrial Management and Data System, Vol. 103, pp. 39-46.

[3] Hall, R. (2003) Knowledge Management in the New Business Environment, Acirrt: University of Sydney.

[4] Hume, C., Pope, N., dan Hume, M., (2011) KM 100 Introductory Knowledge Management For Not-For-Profit Organizations, International Journal of Organizational Behaviour, Vol. 17 (2). pp. 56-71.
[5] Hurley, T. A., Green, C. W., (2005) Knowledge Management and The Non-profit Industry: A Within and Between Approach, Journal of Knowledge Management Practice.

[6] Kotnour, T., Orr, C., Spaulding, J., dan Guidi, J., (1997) Determining yhe Benefit of Knowledge ManagementComputational and Cybernetics and Simulation, IEEE International Conference.

[7] Turban, E., Aronson, J. E., dan Liang, T., (2005) Decision Support System and Intelligent Systems, Prentice Hall, New Jersey.

[8] Nonaka, I., dan Takeuchi, H., (1995) The Knowledge Creating Company, Oxford University Press.

[9] Mohammadi, K., Khanlari, A., dan Sohbari, B., (2009) Organizational Readiness Assessment for Knowledge Management, International Journal of Knowledge Management, Volume 5, Issue 1.

[10] Jalaldeen, R., dan Karim, N. S. A., (2010) Assessing Knowledge Management Readiness in Organizations, IEEE.

[11] Cullom, C. and Cullom, R. S., (2011) Knowledge Management for Non-profits: A Strategy for Organizational Sustainability, Communication of IIMA Vol.11 (2), pp. 13-24.

[12] Miller, D. (1987) The Structural and environmental correlates of business strategy", Strategic Managemet Journal,8, pp.55-76.

[13] Alavi, M., Leidner, D. E., (2001) Review: Knowledge Management and Knowledge Management Systems: Conceptual Foundations and Research Issues. MIS Quarterly, 25 (1).pp. 107-136.

14] Chin, W. W., (1998) The Partial Least Squares Approach for Structural Equation Modeling, in G.A. Marcoulides (Ed.), Modern Methods for Business Research (pp. 295236). London: Lawrence Elbaum Association.

[15] Latan, H., dan Ghozali, I., (2012) Partial Least Square Konsep. Teknik dan Aplikasi Menggunakan Program SmartPLS 2.0 M3. Semarang: Badan Penerbit Universitas Diponegoro.

[16] Davenport,T. H., dan Prusak, L. (1998) Working Knowledge: How Organizations Manage What They Know. Boston: Harvard Business School Press.

[17] Shirazi, A., Mortazavi, S., dan Pour, N. A., (2011) Factors Affecting Employess' Readiness for Knowledge Management, European Journal of Economics, Finance and Administrative Science, Issue 33. pp.167-175.

[18] Sugiarto, A.W., Dwi, A.U., Ridzal, M., Haryanta, P., Zulaiha, S. (2008) Hubungan Kepemimpinan dengan Kesiapan Implementasi Knowledge Management dalam Organisasi, Magister CIO-STEI ITB, Knowledge Management, Leadership in Your Organization.

[19] Kalling, T., (2003) Organizational-internal Transfer of Knowledge and The Role of Motivation: A Qualitative Case Study, Knowledge and Process Management, 10 (2), pp. $115-126$.

[20] Mohanavel, S., Dan Ravindran, S., (2012) A Study on Organizational Readiness for Knowledge Management, European Journal of Scientifics Research, Vol.71 No.2 pp. 152-162.

[21] Merkel, C., Farooq, U., Xiao, L., Ganoe, C., Beth, M. R., John, M.C., (2007) Managing Technology Use and Learning in Non-profit Community Organizations: Methodological Challenges and Opportunities. ACM: CHMIT, USA 